SOBI, Consultant of: Abbvie, Amgen, Biogen, BMS, Celltrion, Galapagos, Glaxo SmithKline, Novartis, Pfizer, Roche, Sanofi-Genzyme, SOBI; clinical trial for Kiniksa, Grant/research support from: Abbvie, Amgen, BMS, Celltrion, Galapagos, Novartis, Pfizer, Roche, Sanofi-Genzyme, SOBI, Merk Sharp \&Dohme, Janssen, Kiniksa, Bhaskar Dasgupta Paid instructor for: Educational grant symposium/workshop for Roche-chugai, Sanofi, and Abbvie, Consultant of: CI UK for the Kiniksa trial, Grant/research support from: Educational grant symposium/ workshop for Roche-chugai, Sanofi, and Abbvie, Bernhard Hellmich Consultant of: Honoraria paid to the institution for participation in the clinical trial, Eamonn Molloy: None declared, Carlo Salvarani: None declared, Bruce C. Trapnell Consultant of: Consultant member of DSMB for Kiniksa., Kenneth $\mathrm{J}$ Warrington Consultant of: Clinical trial support from Eli Lilly and Kiniksa, lan Wicks: None declared, Manoj Samant Shareholder of: Kiniksa Pharmaceuticals, Employee of: Kiniksa Pharmaceuticals, Teresa Zhou Shareholder of: Kiniksa Pharmaceuticals, Employee of: Kiniksa Pharmaceuticals, Lara Pupim Shareholder of: Kiniksa Pharmaceuticals, Employee of: Kiniksa Pharmaceuticals, John F. Paolini Shareholder of: Kiniksa Pharmaceuticals, Employee of: Kiniksa Pharmaceuticals DOI: 10.1136/annrheumdis-2021-eular.2221

\section{AB0371 PATIENTS WITH PROLONGED SYMPTOMS BEFORE GCA DIAGNOSIS DO NOT INCUR HIGHER RATES OF VISUAL LOSS}

V. Yang ${ }^{1}$, C. Mcmaster ${ }^{1,2}$, C. Owen ${ }^{1,2}$, J. Leung ${ }^{1,2}$, R. Buchanan ${ }^{1,2}$, D. Liew ${ }^{1,2}$. ${ }^{1}$ Austin Health, Rheumatology, Heidelberg, Australia; ${ }^{2}$ The University of Melbourne, Medicine, Parkville, Australia

Background: Giant cell arteritis (GCA), if left untreated, confers the threat of serious cranial ischaemic complications including permanent visual loss. Although achieving a prompt and accurate diagnosis remains challenging, early diagnosis is viewed as being paramount in preventing significant morbidity. ${ }^{1}$ This raises the question of whether GCA patients are at greater risk of developing visual sequelae if there is a longer window between symptom onset and presentation.

Objectives: To compare the frequency of lasting visual loss in patients diagnosed with GCA undergoing temporal artery biopsy (TAB) within three months and after three months of symptom onset.

Methods: Patients who underwent TAB from January 2011 to November 2020 were identified from the pathology database of an Australian rheumatology referral centre. The diagnosis of GCA was established for each patient based on either positive TAB or, in the setting of negative TAB, clinical diagnosis by a rheumatologist. Baseline demographics, symptoms and major confounders including age, sex, history of polymyalgia rheumatica or inflammatory arthritis, headache, jaw pain, fatigue, temporal artery tenderness or diminished pulse, and number of 1990 American College of Rheumatology (ACR) classification criteria for $\mathrm{GCA}^{2}$ fulfilled - were manually extracted from electronic medical records, as was the duration between onset of GCA symptoms and TAB, and the presence of visual loss before and after TAB. Logistic regression log-likelihood tests were used to examine the two cohorts presenting before and after three months.

Results: There were 167 patients who underwent TAB during the study period with accessible clinical information. Of these, 31 (19\%) had a delayed presentation of greater than three months from symptom onset. There were no statistical differences in patient demographics between the two groups (Table 1). No patients with delayed presentation experienced lasting, objective visual loss. In contrast, there were three cases in the cohort of patients who presented more promptly; these included two patients who developed permanent unilateral blindness, and one who experienced unilateral vision loss with some improvement at three months of follow-up.

Table 1. Patient characteristics by time from symptom onset to TAB.

\begin{tabular}{lccc}
\hline & $\begin{array}{c}\text { Presentation }<3 \\
\text { months }\end{array}$ & $\begin{array}{c}\text { Presentation } \geq 3 \\
\text { months }\end{array}$ & p-value \\
\hline Age (years) & $73.45 \pm 10.06$ & $69.84 \pm 10.75$ & 0.080 \\
Female & $92(67.65 \%)$ & $20(64.52 \%)$ & 0.738 \\
History of polymyalgia rheumatica & $23(16.91 \%)$ & $4(12.90 \%)$ & 0.586 \\
History of inflammatory arthritis & $6(4.41 \%)$ & $2(6.45 \%)$ & 0.633 \\
Headache & $110(80.88 \%)$ & $23(74.19 \%)$ & 0.406 \\
Jaw pain & $37(27.21 \%)$ & $5(16.13 \%)$ & 0.206 \\
Fatigue & $28(20.59 \%)$ & $6(19.35 \%)$ & 0.878 \\
Temporal artery tenderness or diminished & $46(33.82 \%)$ & $11(35.48 \%)$ & 0.860 \\
$\quad$ pulse & $2.83 \pm 0.99$ & $2.58 \pm 0.89$ & 0.199 \\
ACR classification criteria & & & \\
\hline
\end{tabular}

Conclusion: GCA patients with a lengthier course of symptoms before diagnosis did not experience any enduring visual loss. This may reflect a pattern of more aggressive disease leading to earlier presentation, but further study should explore whether longer symptom duration before diagnosis necessitates a higher degree of clinical concern.

\section{REFERENCES:}

[1] Font C, Cid MC, Coll-Vinent B, López-Soto A, Grau JM. Clinical features in patients with permanent visual loss due to biopsy-proven giant cell arteritis. Br J Rheumatol. 1997 Feb;36(2):251-4. doi: 10.1093/rheumatology/36.2.251. PMID: 9133940.

[2] Hunder GG, Bloch DA, Michel BA, Stevens MB, Arend WP, Calabrese LH, Edworthy SM, Fauci AS, Leavitt RY, Lie JT, et al. The American College of Rheumatology 1990 criteria for the classification of giant cell arteritis. Arthritis Rheum. 1990 Aug;33(8):1122-8. doi: 10.1002/art.1780330810. PMID: 2202311.

Disclosure of Interests: None declared

DOI: 10.1136/annrheumdis-2021-eular.2234

\section{AB0372 TOCILIZUMAB WAS EFFECTIVE IN REFRACTORY ARTERIAL INVOLVEMENT OF BEHCET'S DISEASE: A REAL-LIFE SINGLE- CENTER EXPERIENCE IN CHINA}

H. Zhong ${ }^{1}$, T. Liu ${ }^{1}$, Y. Liu ${ }^{1}$, X. Zhang ${ }^{1}$, Y. Zhou ${ }^{1}$, Y. Su ${ }^{1} .{ }^{1}$ Peking University People's Hospital, Department of Rheumatology and Immunology, Beijing, China

Background: Behcet's disease (BD) is a chronic and relapsing vasculitis, in which major vessel involvement is a main cause of mortality and morbidity. The therapeutic arsenal is mainly composed of classical immunosuppressants. However, when faced with resistance to these drugs, no alternative therapeutic strategy is currently recommended.

Objectives: To assess the efficacy and safety of interleukin 6 receptor inhibitor tocilizumab (TCZ) in refractory arterial involvement of BD in a real-life observational setting.

Methods: 10 patients were enrolled in our center between 2014 and 2019. All patients met the international criteria for $\mathrm{BD}$ and had severe arterial involvement evaluated by echocardiography, angio-Computerized Tomography scan and vascular Doppler. The diagnosis of refractory arterio-BD was based on objective vascular symptoms not explained by any other known disease and non-response to conventional immunosuppressants combined with glucocorticoids therapy. All patients underwent TCZ infusions at $8 \mathrm{mg} / \mathrm{kg}$ every 4 weeks. Concomitant ther apy with immunosuppressants and glucocorticoids was continued. Clinical and imaging findings were assessed before and after TCZ therapy. All adverse events were recorded during follow-up.

Results: All the patients were males, with a mean age of $44.3 \pm 10.5$ years in this study. The mean age at presentation of arterial involvement was $40.8 \pm 9.2$ years old. The patterns of arterial involvement were aneurysm $(n=9)$, stenosis $(n=3)$ and aortic valve lesion $(n=2)$. After a mean follow-up of $26.8 \pm 7.2$ months, TCZ yielded rapid and maintained clinical improvement in 9 patients with complete remission in 6 of them and partial response in 3 of them. Dis continuation of TCZ treatment due to relapse occurred in one case as the enlargement of abdominal aortic aneurysm. The mean glucocorticoid dosage was tapered from $54.5 \pm 20.6 \mathrm{mg} / \mathrm{d}$ to $8.3 \pm 3.6 \mathrm{mg} / \mathrm{d}(\mathrm{p}<0.001)$. And the use of immunosuppressants was tapered in $4(40.0 \%)$ patients. As for serological improvement, the median ESR and CRP levels decreased from $50(2-82$ $\mathrm{mm} / \mathrm{h}$ and $32.9(2.1-62.3) \mathrm{mg} / \mathrm{dL}$ to $4(1-10) \mathrm{mm} / \mathrm{h}(\mathrm{p}<0.001)$ and $2.9(0.2-12.1)$ $\mathrm{mg} / \mathrm{dL}(\mathrm{p}<0.001)$, respectively. Radiologic improvement of artery lesion was demonstrated in $4(40 \%)$ patients. None of the patients had serious adverse events during follow-up.

Conclusion: TCZ was a safe and effective therapeutic option for refractory arterial involvement of $\mathrm{BD}$, with a favorable steroid-sparing effect.

\section{REFERENCES:}

[1] G Hatemi, R Christensen, D Bang, et al. 2018 update of the EULAR recommendations for the management of Behçet's syndrome. Ann Rheum Dis 2018;77(6):808-818.

[2] $\mathrm{Y}$ Ozguler, $\mathrm{P}$ Leccese, $\mathrm{R}$ Christensen, et al. Management of majo organ involvement of Behcet's syndrome: a systematic review for update of the EULAR recommendations. Rheumatology (Oxford). 2018;57(12):2200-2212.

[3] M Akiyama, Y Kaneko, T Takeuchi. Effectiveness of tocilizumab in Behcet's disease: A systematic literature review. Semin Arthritis Rheum. 2020;50(4):797-804. 
Table 1. Tocilizumab therapy in ten cases of refractory arterio-BD

\begin{tabular}{|c|c|c|c|c|c|c|}
\hline Patient & $\begin{array}{l}\text { Age, } \\
\text { year }\end{array}$ & $\begin{array}{c}\text { Disease } \\
\text { duration, } \\
\text { months }\end{array}$ & $\begin{array}{c}\text { Clinical } \\
\text { features }\end{array}$ & $\begin{array}{l}\text { Arterial } \\
\text { lesions }\end{array}$ & $\begin{array}{l}\text { Previous } \\
\text { therapy }\end{array}$ & $\begin{array}{c}\text { Response } \\
\text { at week } \\
24\end{array}$ \\
\hline 1 & & & $\mathrm{O}, \mathrm{G}, \mathrm{P}$ & Stenosis of CA/ SMA/RA/ & Pred/CYC/ & \\
\hline 2 & 34 & 228 & S, I & $\begin{array}{l}\text { SCA, aortic valve prolapse } \\
\text { Dissecting aneurysm of AA }\end{array}$ & MMF & CR \\
\hline 3 & 20 & 24 & $\begin{array}{l}\mathrm{O}, \mathrm{S} \\
\mathrm{O}, \mathrm{G}, \mathrm{P}\end{array}$ & $\begin{array}{c}\text { (Debakey I) } \\
\text { thoracoabdominal aortic }\end{array}$ & $\begin{array}{l}\text { Pred/MMF } \\
\text { Pred/CYC/ }\end{array}$ & PR \\
\hline & 67 & 276 & S, A & aneurysm & TAC & CR \\
\hline $\begin{array}{l}4 \\
5\end{array}$ & 67 & 75 & $\mathrm{O}, \mathrm{S}, \mathrm{U}$ & $\begin{array}{l}\text { Stenosis of LAD/LCX/RCA } \\
\text { Abdominal and coronary }\end{array}$ & Pred /CYC & CR \\
\hline & 50 & 80 & $\mathrm{O}, \mathrm{G}, \mathrm{A}$ & aortic aneurysms & Pred /CYC & Relapse \\
\hline 6 & 48 & 26 & $\mathrm{O}, \mathrm{G}$ & Aortic insufficiency & Pred /CYC & PR \\
\hline 7 & 26 & 147 & $\mathrm{O}, \mathrm{P}, \mathrm{S}, \mathrm{V}$ & Iliac artery aneurysm & Pred /MMF & CR \\
\hline 8 & 49 & 466 & $\mathrm{O}, \mathrm{S}, \mathrm{V}$ & $\begin{array}{c}\text { Thoracoabdominal and coro- } \\
\text { nary aortic aneurysms }\end{array}$ & $\begin{array}{c}\text { Pred /CYC/ } \\
\text { AZA }\end{array}$ & CR \\
\hline $\begin{array}{l}9 \\
10\end{array}$ & 27 & 181 & $\mathrm{O}, \mathrm{P}, \mathrm{S}$ & $\begin{array}{l}\text { Pseudoaneurysm of CCA } \\
\text { Abdominal aneurysm, steno- }\end{array}$ & $\begin{array}{l}\text { Pred /CYC } \\
\text { Pred /CYC/ }\end{array}$ & PR \\
\hline & Male/55 & 354 & $O, P, S$ & sis of LAD/LCX/RCA & AZA & CR \\
\hline
\end{tabular}

*O: oral ulcer; G: genital ulcer; P: pathergy test; S: skin lesions; I: intestinal ulcer; A: arthritis; $\mathrm{U}$ : uveitis; V: venous thrombosis
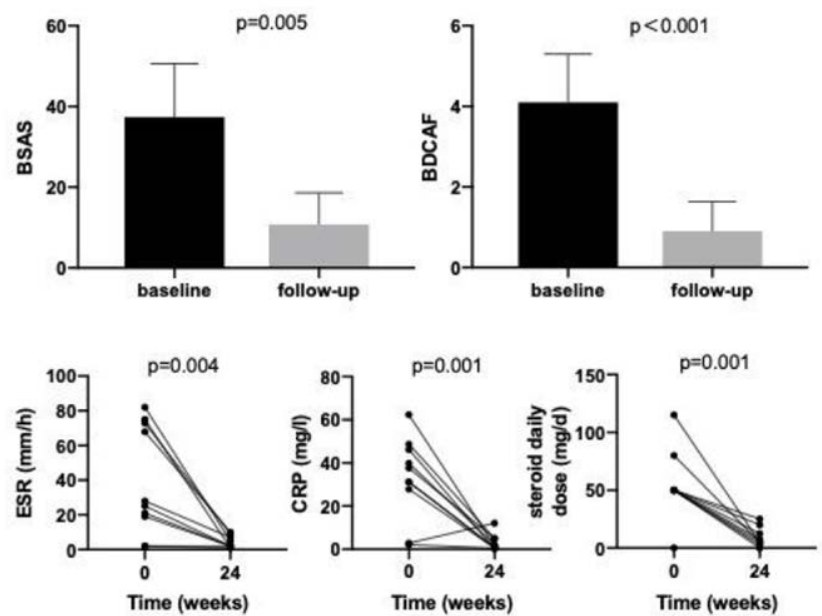

Figure 1. Changes from baseline in BSAS, BDCAF, ESR, CRP and steroid daily dose at 24 weeks

Disclosure of Interests: None declared

DOI: 10.1136/annrheumdis-2021-eular.2302

\section{AB0373 \\ PSYCHOMETRIC PROPERTIES OF OUTCOME MEASUREMENT INSTRUMENTS FOR LARGE VESSEL VASCULITIS: A SYSTEMATIC LITERATURE REVIEW}

G. Boleto ${ }^{1}$, A. Berti ${ }^{2}$, P. A. Merkel ${ }^{3}$, S. Aydin ${ }^{4}$, H. Direskeneli ${ }^{5}$, C. Dejaco ${ }^{6}$, L. Carmona 7 , S. Ramiro $8,9 .{ }^{1}$ Université de Paris, Hôpital Cochin, Rheumatology, Paris, France; ${ }^{2}$ Santa Chiara Regional Hospital and Department of Cellular, Computational and Integrative Biology (CIBIO), University of Trento, Rheumatology, Trento, Italy; ${ }^{3}$ Vasculitis Clinical Research Consortium; Hospital of the University of Pennsylvania, Rheumatology Division, Philadelphia, United States of America; ${ }^{4}$ University of Ottawa Faculty of Medicine, Rheumatology, Ottawa, Canada; ${ }^{5}$ Marmara University, Internal medicine, division of Rheumatology, Istanbul, Turkey; ${ }^{6}$ Medical University of Graz, Rheumatology, Graz, Austria; ${ }^{7}$ Instituto de Salud Musculoesquelética (InMusc), Rheumatology, Madrid, Spain; ${ }^{8}$ Leiden University Medical Center (LUMC), Rheumatology, Leiden, Netherlands; ${ }^{9}$ Zuyderland Medical Center, Rheumatology, Heerlen, Netherlands

Background: Giant cell arteritis (GCA) and Takayasu arteritis (TAK) are two forms of chronic progressive large-vessel vasculitis (LVV) of unknown etiology. In 2016, the OMERACT Vasculitis Working Group proposed the development of a Core Domain Set of outcome measures for LVV including organ and arterial function, fatigue, pain, biomarkers, and death (1). Understanding the psychometric properties of outcome measurement instruments is essential when selecting among instruments to use in research; a summary of such properties for measures of LVV has not been developed.
Objectives: To systematically review and summarize the psychometric properties of outcome measurement instruments used to measure the domains of the OMERACT core domain set for LVV.

Methods: A comprehensive search of several databases (Medline, EMBASE, Cochrane, among others) from inception to July 14,2020 was conducted. Articles were included if they covered psychometric properties of instruments used in LVV. Following the COSMIN and OMERACT frameworks, different psychometric properties (validity, inter- and intra-observer reliability, sensitivity to change, and feasibility) of outcome measurement instruments used in LVV (GCA and TAK) were assessed. Risk of bias was assessed according to the COSMIN checklist. Results: Among the 3534 articles identified, 15 studies focusing on the development or validation of psychometric properties on LVV met the predefined criteria Two were development studies and 13 were validation studies. These studies provided information on 13 instruments: 5 instruments specific to TAK, 2 specific to systemic vasculitides, and 6 general, non-disease-specific instruments. No instruments specific to GCA were identified.

Of the main psychometric properties assessed in the included studies, $40 \%$ had a low, $47 \%$ had moderate, and $13 \%$ had high risk of bias. Construct validity was the property most frequently assessed (in $93 \%$ of the tools) (Figure 1).

In TAK, the Indian Takayasu Clinical Activity Score 2010 (ITAS2010) showed good consistency $(r=0.97)$, reliability (intra-observer, $I C C=0.60$; inter-observer ICC $=0.92$ ) and validity (correlation with Physician Global Assessment (PGA) $(r=0.73))$ for disease activity. Regarding disease damage, the Disease Extent Index-Takayasu (DEI-Tak) showed good validity (correlation with $\mathrm{NIH}$ score $94 \%$, $\mathrm{k}=0.85)$. Non-specific vasculitis instruments such as the Vasculitis Damage Index (VDI) and the Birmingham Vasculitis Activity Score (BVAS) showed moderate validity in the assessment of disease damage in GCA (cumulative glucocorticoid dose and disease duration, $r=0.30$ and $r=0.29$ ) and TAK (cumulative glucocorticoid dose and disease duration, $r=0.29$ and $r=0.25$ ) in the former and disease activity in $\mathrm{GCA}$ in the later (PGA, $\mathrm{r}=0.50$ ).

Six non-vasculitis-specific patient-reported outcomes (PROs) instruments were identified, all showing low to moderate validity in GCA/TAK.

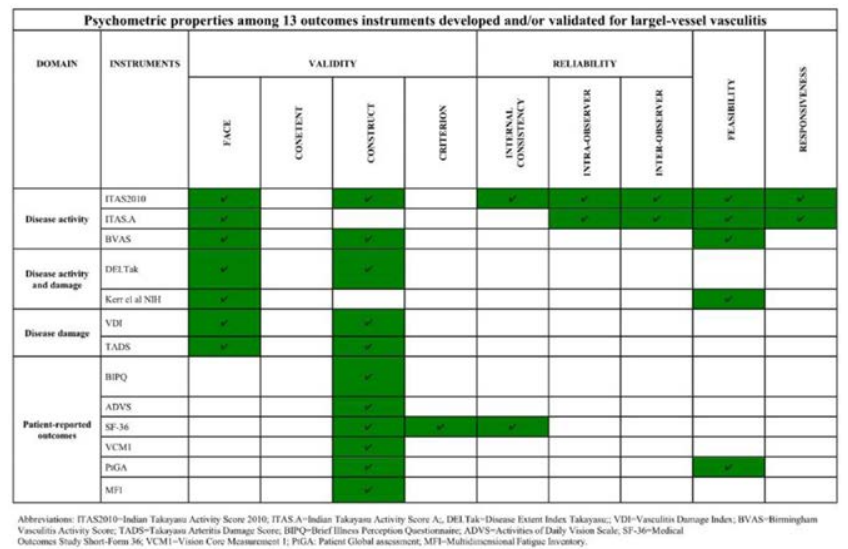

Conclusion: The psychometric properties of 13 outcome measures to study LVV covering the OMERACT domains of disease activity, damage, and patient-reported outcomes were assessed. ITAS2010, DEI-Tak, VDI, and BVAS were the instruments with better psychometric properties for disease activity and/or damage. Disease activity and/or damage instruments specific for GCA, and validated PROs for both GCA and TAK are needed. REFERENCES:

[1] Sreih GA, Alibaz-Oner F, Kermani TA, Aydin SZ, Cronholm PF, Davis T, et al. Development of a Core Set of Outcome Measures for Large-vessel Vasculitis: Report from OMERACT 2016 I The Journal of Rheumatology [Internet]. [cité 26 avr 2020]. Disponible sur: http://www.jrheum.org/content/44/12/1933. long

Disclosure of Interests: None declared

DOI: 10.1136/annrheumdis-2021-eular.2304

\section{AB0374 \\ CHARACTERISTICS OF A GIANT CELL ARTERITIS COHORT IN LATINOAMERICA}

T. Urrego Callejas ${ }^{1,2}$, D. Álvarez ${ }^{3}$, D. Jaramillo Arroyave ${ }^{4,5}$, A. L. VanegasGarcía $^{2,6}, C$. Muñoz ${ }^{2,3,5}$ on behalf of Grupo de Reumatología de la Universidad de Antioquia. ${ }^{1}$ Universidad de Antioquia, Facultad de Medicina, Medellín, Colombia; ${ }^{2}$ Universidad de Antioquia, Grupo de Reumatología Universidad de Antioquia, Medellín, Colombia; ${ }^{3}$ Hospital San Vicente Fundación, Internal Medicine, Rionegro, Colombia; ${ }^{4}$ Grupo de Epidemiología, Universidad CES, 